Jurnal Indonesia Sosial Teknologi: p-ISSN: 2723 - 6609

e-ISSN : 2745-5254

Vol. 2, No. 1 Januari 2021

\title{
PENGARUH PENGEMBANGAN PEGAWAI TERHADAP KINERJA PEGAWAI SEKOLAH TINGGI PERTANAHAN NASIONAL (STPN) YOGYAKARTA
}

\section{Ety Kusummanningsih}

Sekolah Tinggi Pertanahan Nasional

Email: etykusumma04@gmail.com

\begin{abstract}
Organization is an organism. Every organization must continuously grow both quantitatively and qualitatively. This growing ability allows him to be resilient not only in maintaining his existence but also in developing himself steadily in order to achieve goals. One form of formal organization is office organization. This study aims to determine the effect of human resource development on employee performance at Sekolah Tinggi Pertanahan Nasional (STPN) Yogyakarta Branch. Data analysis techniques used are correlation techniques between variables to prove the influence of human resource development on employee performance. Data obtained from employees who at the office of Sekolah Tinggi Pertanahan Nasional (STPN) Yogyakarta branch with a sample of 30 people, based on research conducted and by analyzing the data obtained then the result is to the high relationship between the development of human resources to performance of $0.85 \%$, this means significant coefficient Amounted to 6.845 so that the magnitude of influence between variables Human Resource development on employee performance is $72.25 \%$ where $72.25 \%$ result is the product of the product moment.
\end{abstract}

Keyword: employee development; training; employee performance

\begin{abstract}
Abstrak
Setiap organisasi harus terus menerus bertumbuh baik secara kuantitatif maupun kualitatif. Kemampuan untuk berkembang biaknya ini memungkinkan tangguh bukan saja dalam mempertahankan eksistensinya akan tetapi juga dalam mengembangkan dirinya secara cepat dalam rangka pencapaian tujuan. Penelitian ini bertujuan untuk mengetahui pengaruh pengembangan SDM terhadap kinerja karyawan pada Sekolah Tinggi Pertanahan Nasional (STPN) Yogyakarta. Data diperoleh dari karyawan yang pada kantor Sekolah Tinggi Pertanahan Nasional (STPN) Yogyakarta dengan sampel 30 orang. Berdasarkan penelitian yang dilakukan dengan analisa data yang diperoleh memberikan hasil bahwa terdapat hubungan yang kuat antara peningkatan SDM terhadap Kinerja Karyawan sebesar 0,85 \%. Hal ini berarti koefisien signifikan sebesar 6,845 Jadi besarnya dampaknya Variabel pengembangan sumber daya manusia terhadap kinerja pegawai antara lain secara keseluruhan adalah 72,25\% dimana hasil 72,25\% merupakan hasil perkalian dari produk moment.
\end{abstract}


Kata kunci: pengembangan pegawai; pelatihan; kinerja pegawai.

\section{Pendahuluan}

Salah satu asset penting dalam suatu instansi adalah SDM atau pegawai sebagai perencana dan pelaku dari organisasi. SDM dapat dikatakan asset yang tak ternilai harganya bagi sebuah organisasi karena sumberdaya yang berkualitas akan mampu mendorong kreativitas dan inovasi-inovasi baru yang berkelanjutan dalam suatu organisasi, sehingga organisasi akan terus berkembang dan mencapai kemajuan yang berkelanjutan. Dalam suatu organisasi pegawai mempunyai pikiran, perasaan, keinginan, status, dan latar belakang pendidikan, usia dan jenis kelamin yang heterogen.

Pembinaan pegawai dilakukan di lingkungan Sekolah Tinggi Pertanahan Nasional untuk membentuk pegawai yang berkualitas dengan kemampuan kerja dan loyalitas kerja yang tinggi, sehingga memiliki kinerja yang lebih tinggi; pengembangan pegawai dilakukan di lingkungan Sekolah Tinggi Pertanahan Nasional untuk membentuk kemampuan kerja dan loyalitas kerja yang Mumpuni para karyawan. Loyalitas kerja tinggi, jadi harapkan kinerja luar biasa.

Program pengembangan SDM diperlukan untuk setiap pegawai/karyawan baik pada saat awal memasuki instansi Sekolah Tinggi Pertanahan Nasional dibawah Kementrian ATR/BPN maupun secara berkelanjutan mengikuti tuntutan pekerjaan. Pelatihan di awal pekerjaan bertujuan meningkatkan kompetensi yang harus dimiliki pegawai, yang merupakan persyaratan yang ditetapkan oleh instansi Sekolah Tinggi Pertanahan Nasional. Begitu pula dengan Instansi yang bergerak di bidang pertanahan salah satunya Sekolah Tinggi Pertanahan Nasional (STPN) Yogyakarta haruslah mempunyai gaya kepemimpinan serta pengembangan SDM yang baik demi mencapai tujuan yang telah ditetapkan.

Pengembangan SDM bagi pegawai adalah Belajar dan berlatih secara sistematis untuk meningkatkan kemampuan dan Prestasi kerja mereka saat ini dan persiapan untuk peran tersebut Tanggung jawab yang akan datang (Baharun, 2016).

Kinerja Karyawan adalah hasil dari perilaku anggota organisasi, dimana tujuan aktual yang ingin dicapai adalah dengan adanya perilaku (Sulistiyani, n.d.). Untuk mengukur kinerja, dapat digunakan beberapa ukuran kinerja. Beberapa ukuran kinerja yang meliputi; kuantitas kerja, kualitas kerja, pengetahuan tentang pekerjaan, kemampuan mengemukakan pendapat, pengambilan keputusan, perencanaan kerja dan daerah organisasi kerja.

Sasaran kinerja merupakan suatu pernyataan secara spesifik yang menjelaskan hasil yang harus dicapai, kapan dan oleh siapa yang ingin dicapai tersebut diselesaikan, sifatnya dapat dihitung, prestasi yang dapat diamati, dan dapat diukur. Sasaran kinerja mencakup : perbaikan kinerja, pengembangan pegawai, kepuasan pegawai, keputusan kompensasi, dan keterampilan berkomunikasi (Sinambela, 2012).

Penilaian pegawai merupakan evaluasi yang sistematis dari pekerjaan pegawai dan potensi yang dapat dikembangkan. Penilaian adalah proses penaksiran atau penentuan nilai, kualitas, atau status dari beberapa objek, orang ataupun sesuatu (Sudiro, 2011).

Berdasarkan latar belakang yang telah dikemukakan tersebut maka senada dengan penelitian yang dilakukan oleh Intan Setyowati \& Sri Haryani dengan judul Pengaruh Kepemimpinan, Motivasi Kerja, dan Kompensasi terhadap Kinerja Karyawan pada Restoran Taman Pringsewu Yogyakarta. Berdasarkan hasil penelitian secara 
parsial variabel kepemimpinan berpengaruh signifikanterhadap kinerja karyawan. Secara parsial variabel motivasi berpengaruh signifikanterhadap kinerja karyawan.

Penelitian ini diharapkan dapat menambah ilmu pengetahuan dan wawasan khususnya dalam bidang SDM dan sebagai pelatihan dalam menerapkan serta mengaplikasikan ilmu (akademis) di dunia kerja.

Semoga dapat menambah dan melengkapi bahan bacaan atau literatur di perpustakaan milik

Penelitian ini diharapkan dapat memberikan masukan dan sumbangan pemikiran yang berguna kepada pihak Sekolah Tinggi Pertanahan Nasional (STPN) Yogyakarta agar dapat digunakan sebagai bahan pertimbangan dalam memperbaiki masalah yang berkaitan dengan peningkatan Kinerja Karyawan.

Hasil dari penelitian ini diharapkan menjadi bahan referensi, dapat menambah informasi, sumbangan pemikiran dan menambah pengetahuan pembaca mengenai pengaruh pengembangan pegawai terhadap Kinerja Karyawan.

\section{Metode Penelitian}

Jenis Penelitian yang digunakan dalam penelitian ini adalah penelitian terkait dengan menggunakan metode kuantitatif, gunakan rumus statistik untuk membantu menganalisis data dan fakta yang diperoleh. Menurut (Tarigan \& Nasution, 2014) sampel adalah kelompok kecil yang kita amati dan merupakan bagian dari populasi sehingga karakteristik populasi juga dimiliki oleh sampel. Menurut (Suharsimi, 2010) mengatakan :"Jika jumlah populasinya kurang dari 100 orang, maka jumlah sampelnya diambil keseluruhan. Tapi jika jumlahnya lebih dari 100 orang, maka bisa diambil 10 $15 \%$ atau 15 - 25\% dari jumlah populasinya.

Penelitian ini dilakukan pada kantor Sekolah Tinggi Pertanahan Nasional (STPN) Yogyakarta. Populasi dalam penelitian ini adalah seluruh pegawai Sekolah Tinggi Pertanahan Nasional (STPN) Yogyakarta, sedangkan sampel yang ditarik secara acak adalah sebahagian pegawai tetap, sehingga jumlah sampel yang diambil sebesar $15 \%$ x $200=30$ orang.

Untuk membantu menggunakan teknik penentuan skor dalam penelitian. Teknik pengukuran skor yang digunakan adalah dengan skala ordinal untuk menilai jawaban kuesioner responden.

Studi Pustaka adalah salah satu metode Pengumpulan data melalui buku bacaan, jurnal, referensi dan Mata kuliah yang berhubungan dengan penelitian dan penelitian sebelumnya terkait Riset yang sedang berlangsung. Skala yang digunakan dalam instrumen penelitian tersebut adalah skala likert. Dengan skala likert, maka variabel yang akan diukur dijabarkan menjadi indikator variable (Suryana et al., 2013)

\section{Hasil dan Pembahasan}

Pengembangan Pegawai di lingkungan Sekolah Tinggi Pertanahan Nasional dilakukan untuk membentuk pegawai yang berkualitas dengan kemampuan kerja, dan mempunyai loyalitas kerja yang tinggi, sehingga diharapkan berkinerja tinggi. Sekolah Tinggi Pertanahan Nasional yang merupakan bagian dari Kementerian Agraria dan Tata Ruang/Badan Pertanahan Nasional tentunya membutuhkan pegawai-pegawai yang mempunyai kompetensi yang tinggi sehingga diharapkan mampu untuk menyelesaikan beban kerja yang diberikan serta dapat berkontribusi yang maksimal dalam perannya memajukan Sekolah Tinggi Pertanahan Nasional sesuai visi dan misinya. 
Pegawai Sekolah Tinggi Pertanahan yang merupakan Aparatur Sipil Negara tentunya diharapkan mempunyai ketrampilan dan pengetahuan yang memadai untuk mendukung terciptanya Kinerja Karyawan yang tinggi, dengan demikian dapat mendukung tercapainya program kerja yang telah ditetapkan. Sekolah Tinggi Pertanahan Nasional memerlukan SDM atau pegawai yang berkualitas untuk pelaksanaan kinerja yang sesuai dengan tugas pokok fungsi yang dimiliki. Pegawai Sekolah Tinggi Pertanahan Nasional merupakan pegawai yang diharapkan membawa kemajuan bagi instansi untuk dapat bekerja lebih baik lagi dalam kapasitasnya sebagai Aparatur Sipil Negara dan sebagai pelayanan masyarakat, khususnya para mahasiswa yang menempuh pendidikan di Sekolah Tinggi Pertanahan Nasional.

Koefisien determinan digunakan untuk mengetahui berapa persen (\%) besarnya pengaruh variabel bebas terhadap variabel terikat, dalam penelitian ini, untuk melihat berapa besar pengaruh pengembangan SDM (variabel $\mathrm{x}$ ) terhadap Kinerja Karyawan (variabel y). Setelah dilakukan perhitungan determinan diatas maka besarnya antara variabel $\mathrm{X}$ (pengembangan SDM) terhadap variabel Y (Kinerja Karyawan) adalah sebesar $72.25 \%$, artinya pengembangan SDM yang dilakukan oleh Sekolah Tinggi Pertanahan Nasional (STPN) Yogyakarta melalui pengembangan diklat pelatihan dan tugas belajar, kegiatan non diklat berpengaruh terhadap Kinerja Karyawan Sekolah Tinggi Pertanahan Nasional (STPN) Yogyakarta sebesar 72,25\% dimana hasil 72,25\% merupakan hasil perkalian dari Product moment, dimana product moment merupakan rekapitulasi hasil jawaban responden tentang bagaimana kegiatan diklat dan tugas belajar pada Sekolah Tinggi Pertanahan Nasional (STPN) Yogyakarta, sedangkan sisanya $27,75 \%$ pengaruh kinerja dipengaruhi faktor lain yang bukan berasal dari penelitian ini. Misalnya karena tujuan dan target yang ingin dicapai instansi sekolah, sehingga mengharuskan para pegawai harus memilki kinerja kerja yang lebih baik atau karena pemberian tunjangan gaji dan reward sehingga memacu para pegawai untuk bekerja lebih baik sehingga dapat dipastikan 27,75\% pengaruh kinerja tersebut diluar penelitian yang akan dilakukan ini.

Kinerja Karyawan Sekolah Tinggi Pertanahan Nasional (STPN) Yogyakarta dapat dikatakan baik karena dengan pengembangan SDM yang telah baik akan meningkatkan Kinerja Karyawan pada instansi tersebut, terbukti adanya pengaruh antar kedua variabel yang dikategorikan tinggi, dan juga berdasarkan hasil uji test "t" dapat dilihat koefisien korelasi antara pengembangan SDM terhadap karyawan sebesar 6.845 adalah signifikan, artinya koefisien korelasi tersebut dapat diterima.

Pengaruh pengembangan SDM terhadap Kinerja Karyawan Sekolah Tinggi Pertanahan Nasional (STPN) Yogyakarta dalam kategori tinggi ini terlihat berdasarkan hasil analisis determinasi maka dapat diketahui bahwa besarnya pengaruh antar variabel $\mathrm{X}$ (pengembangan SDM) terhadap variabel Y (Kinerja Karyawan) adalah sebesar 72.25\% sedangkan sisanya $27.75 \%$ dipengaruhi faktor lain diluar penelitian ini.

\section{Kesimpulan}

Berdasarkan hasil penelitian dan pembahasan, maka dalam penelitian ini dapat disimpulkan bahwa dari hasil analisis data yang dilakukan Pengembangan SDM pada Instansi Sekolah Tinggi Pertanahan Nasional (STPN) Yogyakarta dapat dikategorikan baik, hal tersebut berdasarkan hasil kuesioner tentang pengembangan SDM, seluruh responden menjawab pertanyaan dengan jawaban dengan nilai tinggi sehingga dari hasil kuesioner dilakukakan analisis korelasi Product Moment untuk melihat bagaimana pengembangan SDM. 
Pengembangan pegawai Sekolah Tinggi Pertanahan Nasional (STPN) Yogyakarta baik melalui pelatihan atau diklat, maupun tugas belajar mempunyai pengaruh terhadap Kinerja Karyawan STPN, dimana kinerja semakin meningkat, sehingga beban kerja yang diberikan kepada pegawai yang bersangkutan dapat diselesaikan dengan baik, dan terpenuhinya target pegawai terhadap beban kerjanya. Hal ini tentunya sangat diharapkan agar hasil dari pengembangan pegawai tersebut dikatakan berhasil mempengaruhi Kinerja Karyawan di Sekolah Tinggi Pertanahan Nasional (STPN) Yogyakarta.

Beberapa saran dan pertimbangan yang disajikan berdasarkan penelitian ini adalah perlunya peningkatan Kinerja Karyawan tidak hanya pada pelatihan dan tugas belajar saja, tetapi juga melalui peningkatan SDMnya dan faktor-faktor lain, seperti : keselamatan dan kesejahteraan pegawai, promosi jabatan, yang bisa meningkatkan Kinerja Karyawan yang selalu ditekankan pada kualitas pegawai dan mutu pelaksanaan diklat sehingga dapat memberikan kontribusi pemikiran untuk dapatkan hasil kerja yang maksimal dan dapat berkembang karirnya seperti dengan menjadi dosen ataupun pejabat fungsional di lingkungan Sekolah Tinggi Pertanahan Nasional (STPN) Yogyakarta. 
Ety Kusummanningsih

\section{Bibliography}

Amalia, S., \& Fakhri, M. (2016). Pengaruh Motivasi Kerja Terhadap Kinerja Karyawan pada PT. Gramedia Asri Media Cabang Emerald Bintaro. Jurnal Computech \& Bisnis. 10(2): 119-127.

Ariesta Angga dan Dewi Mudiartha Utama, 2016. Pengaruh Pengembangan Karir Terhadap Kinerja Karyawan Melalui Mediasi Motivasi Kerja Pada Karya Mas Art Gallery, Jurnal Manajemen Unud, Vol. 5,No.9.

Agwu, Mba Okechukwu and Tonye Ogiriki. 2016. Human Resource Development and Organizational Performance in the Nigeria Liquefied Natural Gas Company Limited,Bonny. Journal of Management and Sustainability; Vol. 4, No. 4; 2014 ISSN 1925-4725 E-ISSN 1925-4733

Baharun, Hasan. (2016). Manajemen kinerja dalam meningkatkan competitive advantage pada lembaga pendidikan Islam. At-Tajdid: Jurnal Ilmu Tarbiyah, 5(2), 243-262.

B a g u s , D a n n y . (2017). Pengaruh Pengembangan Dan Motivasi Kerja Terhadap Kinerja Karyawan PTBNP Bandung.

Hameed, Abdul and Aamer Waheed. 2017. Employee Development and Its Affect on Employee Performance A Conceptual Framework. International Journal of Businessand Social Science Vol. 2 No. 13 [Special Issue - July 2011]

Muda, Iskandar and Ahmad Rafiki. 2014. Human Resources Development and Performance of Government Provincial Employees: A Study in North Sumatera, Indonesia. Journal of Economics and Behavioral Studies Vol. 6, No. 2, pp. 152162, Feb 2014 (ISSN: 2220-6140)

Kusdiah, Yuli. 2017. Pengaruh Pemgembangan SDM Terhadap Motivasi Kerja Karyawan Pada Pdam Kabupaten Gowa. Jurnal ILTEK,Volume 7, Nomor 13, April 2012

Rusminingsih, Diah. 2010. Pengaruh Pengembangan SDM Terhadap Produktivitas Kerja Karyawan Pada PT. Cakra Guna Cipta Malang. Jurnal Modernisasi, Volume 6, Nomor 1, Pebruari 2010

Purnama, Husna. 2018. Pengaruh Pengembangan SDM Terhadap Produktivitas Kerja Karyawan Pada CV Sumber Alam Lampung Selatan. Jurnal Sains dan Inovasi 6(1)48-53(2010)

Sinambela, Lijan Poltak. (2018). Kinerja Karyawan Teori Pengukuran dan Implikasi. Yogyakarta: Graha Ilmu.

Sudiro, Achmad. (2016). Perencanaan Sumberdaya Manusia. Universitas Brawijaya Press. 
Suharsimi, Arikunto. (2016). Prosedur penelitian: suatu pendekatan praktik (edisi revisi). Jakarta: Rineka Cipta, 1.

Sulistiyani, Ambar Teguh. (n.d.). Rosidah, 2003, Manajemen SDM. Yogyakarta: Graha Ilmu.

Sintaasih dan Balbed.2019 Pengaruh Pengembangan Karir Terhadap Kinerja Karyawan Melalui Pemediasi Motivasi Kerja Karyawan. Jurnal Manajemen Jurnal Unud. Vol. 8, No. 7.

Suryana, Sugiyono, Sekaran, Uma, Lee, Ss, Stearns, Tm, \& Geoffrey, G. Meredith. (2017). Metode Penelitian Kuantitatif, Kualitatif, dan R\&D. International Journal of Management, 56(8), 143-154.

Tarigan, Christoper Giovani, \& Nasution, M. Arif. (2014). Pengaruh Pengembangan SDM Terhadap Kinerja Karyawan Pada PT. PLN Cabang Binjai. Publikauma: Jurnal Administrasi Publik Universitas Medan Area, 2(2), 146-153.

Wattimena, Fransina. 2017. Implementasi Strategi Pengembangan SDM dan Dukungan Organisasi Terhadap Peningkatan Kualitas Dosen Fakultas Ekonomi Universitas Pattimura Ambon. Jurnal Manajemen Dan Kewirausahaan, Vol.12, No. 2, September 2010: 195-208 